\title{
ENERGY HARVESTING USING KINETIC ENERGY OF VEHICLES
}

\author{
Mirsad Hyder Shah \\ Ex-Fellow, Department of Electrical Engineering, DHA Suffa University. Karachi, (Pakistan). \\ E-mail: itsmirsadhyder@yahoo.com ORCID: https://orcid.org/0000-0003-2476-5887 \\ Gasim Othman Alandjani \\ Associate Professor, Computer Science and Engineering Department. Yanbu University College, Yanbu Industrial City, \\ (Kingdom of Saudi Arabia). \\ E-mail: alandjanig@rcyi.edu.sa ORCID: https://orcid.org/0000-0003-0321-7013

\begin{abstract}
Maryam Asghar
Ex-Fellow, Department of Electrical Engineering, DHA Suffa University. Karachi, (Pakistan). E-mail: maryamasghar1998@gmail.com ORCID: https://orcid.org/0000-0001-5356-7818
\end{abstract}

Recepción: 27/02/2020 Aceptación: 07/05/2020 Publicación: 15/06/2020

Gitación sugerida:

Shah, M. H., Alandjani, G. O., y Ashgar, M. (2020). Energy harvesting using kinetic energy of vehicles. 3C Tecnología. Glosas de innovación aplicadas a la pyme, 9(2), 113-126. http://doi.org/10.17993/3ctecno/2020.v9n2e34.113-126 


\section{ABSTRACT}

With the increasing global energy demand, clean and affordable sources of energy are being adopted over time. Road Power Generation (RPG) is thus an alternate to conventional electricity generation. RPG technologies generate electrical power from vehicles by harnessing their kinetic energy. The most common RPG technology is RPG by speed breaker mechanism. However, this paper will discuss the construction of a novel Electro-Mechanical system which can be employed on the surface of a road and thus can produce electricity of up to six kilowatts per day. A vehicle induces reciprocating linear motion into the RPG flip plates which is then converted to rotary motion via rack and pinion. This angular motion is converted to electricity via a PMDG generator which can be used to power streetlights. This method of generating electricity is called RPG by flip plate mechanism or RPG by reciprocating linear motion.

\section{KEYWORDS}

Flip plate mechanism, Road power generation, Energy harvesting, Rack and Pinion, Reciprocating Linear Motion, Kinetic Energy of Vehicles. 


\section{INTRODUCTION}

The need of alternate energy sources is not a debate but a necessity in this modern era. The demand of clean and affordable energy sources led to the breakthrough of renewable energy sources. RPG is a similar advancement which can be argued to be a green source of energy. With the increasing number of cars on roads, RPG should be the base of smart cities.

Previous RPG methods have not been successful because of the following reasons:

- They require the vehicles to slow down their movement because they have the characteristics of a speed breaker.

- The wear and tear of the RPG unit requires substantial maintenance; specifically the springs.

- The safety of the vehicles to step on these units is a major challenge.

RPG by flip plate mechanism addresses the above issues significantly. This foot unit utilizes the hortizontal stroke of the vehicle and as a result; the vehicles do not have to slow down anymore. The maintenance of the RPG unit is very easy, and any malfunction does not endanger the vehicle above.

\subsection{LITERATURE REVIEW}

\subsubsection{RPG BY PIEZOELECTRIC MATERIAL}

The piezoelectric material as discussed above is a handy way to generate electricity but has several drawbacks when applied to the concept of RPG (Lee et al., 2010).

- Sound waves bend the piezoelectric material, creating a changing voltage.

- Crystal is prone to crack if overstressed.

- It may get affected by long use at high temperatures. 


\subsubsection{RPG BY SPEED BREAKERS}

Road Power generation by speed breakers is the most common RPG method as of now, but it also has several drawbacks (Rao, Kumar, \& Suresh, 2014):

- Cannot be installed on main roads or highways since it requires the car to stop.

- If too much pressure is applied the spring can deform.

- If too less pressure is applied, the unit may not produce any electricity.

\subsubsection{RPG BY HARNESSING THE WASTED HEAT ENERGY}

This type of road power generation is a prediction made in the domain of RPG. It can be set up by employing heat absorbing material to capture the wasted heat energy of tires. It is predicted to have the following pitfalls:

- Very high setup cost.

- Material quality is very rare.

- High maintenance cost.

\section{METHODOLOGY AND RESEARCH}

The RPG unit is 4 foot wide, 3 foot long and 3 foot high in structural dimension. The frame which holds everything in place is made up of high tensile steel or can be made of any material with high stress tolerance. It has the following parts:

\subsection{FLIP PLATES}

First, let us discuss the dimensions of the flip plates. A foot, checkered, mild steel sheet with a gauge of $10 \mathrm{~mm}$ was cut to achieve a special design as shown in Figure 1. As a result, the rectangular sheet was 
transformed into two female (Flip plate A and Flip plate C) and one male flip plate (Flip plate B). The two female flip plates with dimensions of inches were welded at the corners of the frame. The male flip plate or the moving plate was inches in dimension. The female flip plates had teeth of inches while the male flip plate's teeth dimensions were inches.

Second, four springs at positions A1-A2, B1-B2, C1-C2 and D1-D2 hold the flip plate B and flip plate $\mathrm{C}$ together. As a result, a distance of $5 \mathrm{~cm}$ is achieved between the flip plate A and flip plate B under normal circumstances.

Third, to minimize the friction employed and to smoothen the male flip plate's movement; small wheeled cars were tightened with the male flip plate at positions E,F,G and $\mathrm{H}$ through nuts and bolts. These small wheeled cars were placed inside a rack and tightened at the top of the frame.

With this arrangement, when we drag the male flip plate towards the female flip plate, it would roll over the frame and this movement will be stored as elastic potential energy in the spring. Finally when we let go of the male flip plate, it would come back to its original position.

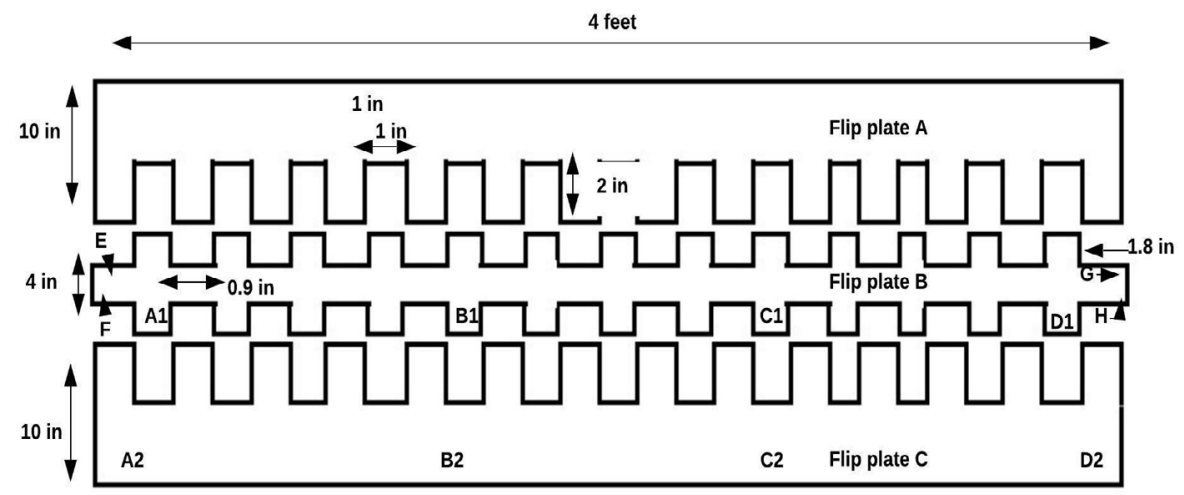

Figure 1. Detailed dimensions of flip plates. 


\subsection{UPPER SHAFT}

The purpose of this shaft is to produce rotary motion from the linear motion of the flip plate. To interconnect the flip plate system with the upper shaft, three racks were placed directly upon three pinions which were mounted on the shaft. These racks were welded under Flip plate B at equi-distant positions and placed directly upon the upper shaft. Each of these racks had 64 teeth, were 12 inches in diameter and had a gauge of 3 inches.

The upper shaft had a $20 \mathrm{~mm}$ gauge and had 3 circular pinions mounted on it. Each pinion had 64 teeth, a diameter of 5 inches and thickness same as that of the rack. Each pinion had a clutch bearing fitted at the center and then passed through the $20 \mathrm{~mm}$ shaft. The shaft also has a type A sprocket mounted on it with 66 teeth. The shaft was placed just below the rack arrangements by the means of pillow blocks and fitted in the RPG unit.

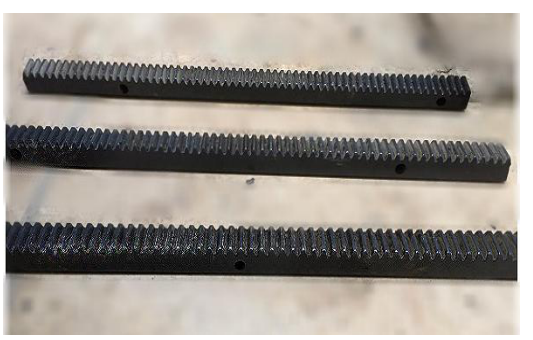

Figure 2. Picture of racks.

Figure 3. Picture of Pinion.

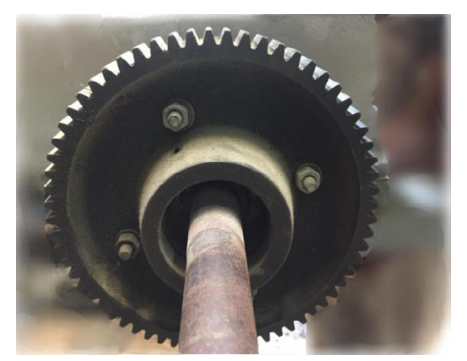




\subsection{LOWER SHAFT}

The purpose of this shaft is to couple the RPG unit with the Generator. To interconnect the upper and the lower shaft, a type B sprocket is mounted on the lower shaft and connected via a chain drive with the type A sprocket with 22 teeth.

The lower shaft is $20 \mathrm{~mm}$ in gauge and consists of a $10 \mathrm{~kg}$ flywheel having a diameter of 10 inches. Furthermore, to transfer the energy of this shaft to the DC generator, one spur gear is also mounted on the lower shaft. This shaft was also held using pillow blocks and fitted in the RPG unit.

\subsection{POWER GENERATION AND STORAGE}

The other spur gear was fitted on the shaft of a 24V, $1050 \mathrm{rpm}, 1.1 \mathrm{~kW}$ PMDC generator. After the generator does some useful work, the voltage produced was fed to a buck/boost converter. This buckboost converter steps up or down the input voltage to a constant $13 \mathrm{~V}$ DC output. This voltage was then fed to a charge controller which cuts off the supply once the battery is fully charged.

An Arduino Uno was connected to a voltage sensor module and a current sensor module to monitor the average energy production per vehicle.

Table 1. Comparison of Generator characteristics.

\begin{tabular}{|c|c|c|c|c|}
\hline GENERATORS & $\begin{array}{c}\text { SPEED } \\
\text { REGULATION }\end{array}$ & STARTING TORQUE & OTHER FACTORS. \\
\hline DC SHUNT & Good & Poor & $\begin{array}{c}\text { Field winding can be separately } \\
\text { excited or same as Armature. } \\
\text { Expensive }\end{array}$ \\
\hline DC SERIES & Good & $\begin{array}{c}\text { Depends upon } \\
\text { armature Resistance }\end{array}$ & $\begin{array}{c}\text { Cannot be used when constant } \\
\text { speed is required. }\end{array}$ \\
\hline DC COMPOUND & Good & Good & Very expensive \\
\hline PC GENERATORS & $\begin{array}{c}\text { None in } \\
\text { Synchronous }\end{array}$ & High & Smaller in size \\
\hline
\end{tabular}

Source: (Edvard, 2015). 


\section{WORKING OF THE RPG UNIT}

The RPG unit is placed on the same level as the road surface. When a moving car runs over the RPG unit, the male flip plate is displaced $5 \mathrm{~cm}$ to the female flip plate. This displacement causes potential energy to be stored in the springs. When the spring releases that stored energy (by bringing the male flip plate back to its original position), the racks rotate the pinions by a circumference of $5 \mathrm{~cm}$. This rotation induces a unidirectional rotation in the upper shaft, since the pinions have clutch bearings at their centers. As a result, a uniform, unidirectional, rotation is produced (Chandwani, Patel, \& Kothari, 2017).

This rotation in the upper shaft is transferred to the lower shaft by means of a chain drive sprocket. Since torque and angular velocity are inversely proportional, the upper shaft will have high torque and low angular velocity compared to the lower shaft which will have lower torque and a higher angular velocity.

The flywheel in the lower shaft helps to resist the change in the rotational speed of the lower shaft due to its high moment of inertia. As a result, energy is stored in the flywheel and released to the generator which converts the energy stored into electrical energy (Fatima \& Mustafa, 2011). 


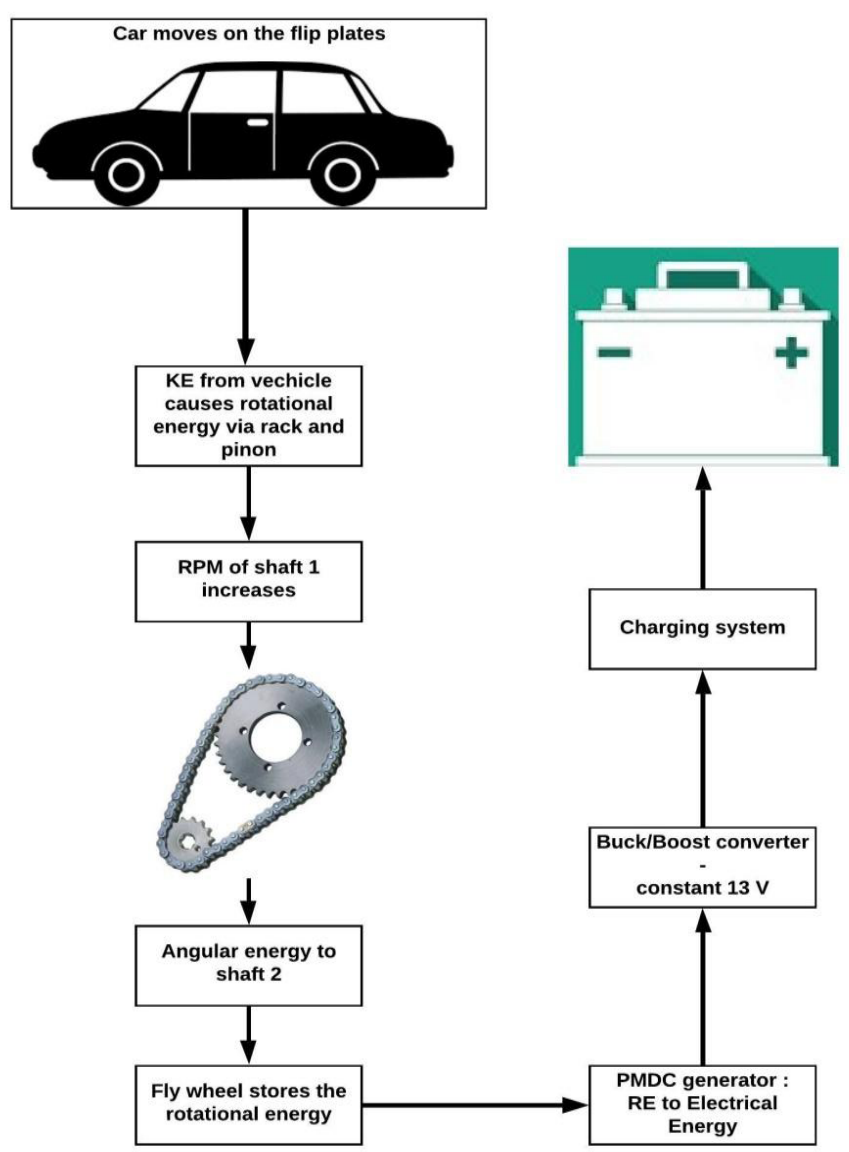

Figure 4. Block of diagram of RPG Working. Source: (Gowri et al., 2018).

\section{CALCULATIONS}

If we suspend a block of mass $1 \mathrm{~kg}$ vertically, we can find out the spring constant (k) by simply measuring the displacement $(\mathrm{x})$. 
According to Hooke's law,

$$
F=k x
$$

Since the vertical force acting upon the block will simply be the weight,

$$
(W=m g) \text { of the block. } F=\omega
$$

Equating (i) \& (ii), we get:

$$
k x=m g
$$

Where $\mathrm{m}$ is the recorded mass of the object, and $\mathrm{x}$ is the extension of the string.

Where $=10 \mathrm{~kg}, g=9.8 \mathrm{~m} / \mathrm{s}^{\wedge} 2, x=8.64 \mathrm{~cm}$,

$$
\begin{gathered}
k=\frac{80 * 9.8}{0.0864} \\
k=1133 \mathrm{~N} / \mathrm{m}
\end{gathered}
$$

The force on each rack is given below with distance between the racks is $5 \mathrm{~cm}$ :

$$
\begin{gathered}
F=k x \\
F=1133 * \frac{5 \mathrm{~cm}}{100} \\
F=56.69 \mathrm{~N}
\end{gathered}
$$

Since there are three racks employed:

$$
\begin{aligned}
& F_{t}=F_{1}+F_{2}+F_{3} \\
& \tau_{t}=\sum_{i=1}^{3} \ldots \tau_{i} \\
& \tau_{t}=\tau_{1}+\tau_{2}+\tau_{3} \\
& \tau_{t}=r_{1} F_{1}+r_{2} F_{2}+r_{3} F_{3}
\end{aligned}
$$

Since $r_{1}, r_{2} \& r_{3}$ are the radii of each of the pinions, $r_{1}=r_{2}=r_{3}=r=12,7 \mathrm{~cm}$ 


$$
\tau_{t}=r\left(F_{1}+F_{2}+F_{3}\right) \quad(v i i)
$$

Substituting Equ. (iii)

$$
\begin{array}{cc}
\tau_{t}=F_{t} & \\
\tau_{t}=\frac{12.7}{100} *(56.69 * 3) \\
\tau_{t}=21.59 \mathrm{N.m}
\end{array}
$$

From Newton's second law:

$$
\begin{aligned}
\tau_{t} & =I * \alpha \\
\tau_{t} & =I * \frac{\omega_{L}}{f}
\end{aligned}
$$

Where, is angular velocity of shaft and is the inertia

$$
\begin{aligned}
I=\frac{1}{2} & * m * r^{2} * 3 \\
I & =\frac{1}{2} * \frac{320}{1000} *\left(\frac{12.7}{100}\right)^{2} * 3 \\
I & =0.007774192 \mathrm{~kg} * \mathrm{~m}^{2}
\end{aligned}
$$

From equation (x):

$$
\begin{gathered}
\omega_{L}=\frac{\tau_{t} * t}{I} \quad(x i i) \\
\omega_{L}=\frac{21.59 * t}{0.007774192}
\end{gathered}
$$

Assuming that the car on the RPG unit is driving at a speed of $50 \mathrm{~km} / \mathrm{hr}$ which translates as $13.88 \mathrm{~m} / \mathrm{s}$ 13.88 meters $\longrightarrow 1$ second

That means

$$
1 \text { meter } \longrightarrow \frac{1}{13.88} \text { seconds }
$$

Since the distance between the plates is $5 \mathrm{~cm}$

$$
0.05 \text { meters } \longrightarrow \frac{0.05}{13.88} \text { seconds }
$$




$$
\begin{gathered}
\omega_{L}=\frac{21.59}{0.007774192} \times \frac{0.05}{13.88} \\
\omega_{L}=10.05 \mathrm{rad} / \mathrm{sec}
\end{gathered}
$$

\section{Converting to RPM}

$$
\omega_{L}=95.48 \mathrm{rpm}
$$

From chain drive we know

$$
\frac{\omega_{2}}{\omega_{1}}=\frac{\text { Teeth of large sprocket }}{\text { Teeth of small sprocket }} \quad \text { (xiii) }
$$

Where is the angular velocity on shaft 2 .

Teeth of large sprocket $=66$ and teeth of small sprocket $=22$

$$
\begin{gathered}
\omega_{2}=95.48 * \frac{66}{22} \\
\omega_{2}=286.44 \mathrm{rpm}
\end{gathered}
$$

The shaft transfers this angular velocity to the sprocket of the generator with a gear ratio of $85 / 17$

$$
\frac{\omega_{3}}{\omega_{2}}=\frac{\text { Teeth } \text { of large sprocket }}{\text { Teeth of small sprocket }}(x i v)
$$

Teeth of large sprocket $=85$ and teeth of small sprocket $=17$

$$
\begin{aligned}
& \omega_{3}=286.4417 * \frac{85}{17} \\
& \omega_{3}=1432.20 \mathrm{rpm}
\end{aligned}
$$

The EMF produced by the generator is represented by the equation below:

$$
E_{g}=K * \varphi * \omega \quad(x v)
$$

Where $\mathrm{K}$ is a constant, $\varphi$ is the flux and $\mathrm{w}$ is the angular velocity. 


\section{RESULTS AND CONCLUSION}

In this paper an Electro-mechanical system was designed and implemented. It is clear that the factors affecting the power production is the spring's constant ' $\mathrm{k}$ ' and the distance between the plates. Since it was not possible for us to continuously change the distance between the flip plate A and B, we decided to change the spring constant. Upon experimentation, following results were obtained.

Table 2. Results.

\begin{tabular}{|c|c|c|c|}
\hline \multicolumn{1}{|c|}{} & Spring Constant & $\begin{array}{c}\text { Power produced per- } \\
\text { car }\end{array}$ & $\begin{array}{c}\text { Expected Power } \\
\text { produced per day }\end{array}$ \\
\hline 1. & $1133 \mathrm{~N} / \mathrm{m}$ & 3 Watts & 6 kilo Watts \\
\hline 2. & $1278 \mathrm{~N} / \mathrm{m}$ & 3.6 Watts & 7.2 kilo Watts \\
\hline
\end{tabular}

\section{REFERENCES}

Ghandwani, A., Patel, A. N., \& Kothari, A. (2017). Design of Road Power Generator (RPG): an Alternate Energy Source for sustainability. International fournal of Engineering and Technology, 9(2), 494-501. https://www.researchgate.net/publication/317330491_Design_of_Road_Power_ Generator_RPGan_Alternate_Energy_Source_for_Sustainability

Fatima, N., \& Mustafa, J. (2011). Production of electricity by the method of road power generation. International fournal of Advances in Electrical and Electronics Engineering, 1(1), 9-14. http:// citeseerx.ist.psu.edu/viewdoc/download?doi=10.1.1.645.9199\&rep=rep $1 \&$ type=pdf

Gowri, G., Saranya, N., Shanmugapriya, T., \& Bommirani, B. (2018). Road Power Generation (RPG) By Flip Plate Mechanism. In First International Conference on NexGen Technologies. Sengunthar Engineering College Tiruchengode, Namakkal Dist. Tamilnadu (India). http://data.conferenceworld.in/ NEXGEN/80.pdf

Lee, J. Y., Lee, M. K., Oh, J. G., \& Kim, K. S. (2010). Study on the Energy Conversion from the Dynamic Load of Vehicles on the Road Using Piezoelectric Materials. Materials Science Forum, 658, 57-60. https://doi.org/10.4028/www.scientific.net/msf.658.57 
Rao, A. P., Kumar, A. K., \& Suresh, S. (2014). Power generation from speed breaker by rack and ratchet mechanism. International Fournal of Current Engineering and Technology, 1(2), 549-552. http:// Dx.Doi.Org/10.14741/Ijcet/Spl.2.2014.104

Edvard. (2015, January 7). 4 types of DC Motors and their Characteristics. Electrical Engineering Portal. https:/ / electrical-engineering-portal.com/4-types-of-dc-motors-and-their-characteristics 